\title{
Double Orphanhood: A Psychosocial Barrier to Assimilation of Learning Schemes in Child-Headed Households
}

\author{
Emily Ganga \\ Great Zimbabwe University, Faculty of Education, Department of Educational Foundations, \\ PO Box 1235, Masvingo, Zimbabwe \\ E-mail: emilyganga@gmail.com
}

\section{C. Maphalala}

University of South Africa, College of Education, Department of Curriculum \& Instructional Studies, PO Box 392, Unisa, 0003, South Africa E-mail:mphalmc@unisa.ac.za

\section{Doi:10.5901/mjss.2013.v4n13p499}

\begin{abstract}
'Orphanhood' is among the many undesirable phenomena within developing countries which seem to be precipitated by escalating parental deaths mostly rooted in the devastating effects of HIVIAIDS and poverty. This case study investigated double orphanhood and its effects on the cognition and learning of orphans and vulnerable children (OVC) living within childheaded households (CHHs) in Zimbabwe. The qualitative enquiry is hinged on constructivist views in Erikson's psychosocial development theory. The triangulated data was collected through participant observations, an open-ended questionnaire, interviews, and focus group discussions held at four secondary schools. The purposefully selected participants comprised 20 double orphans and vulnerable children, four headmasters, eight teachers, one Education Officer and one Social Welfare officer, making a total sample of 34. The findings revealed that though most OVC try to remain resilient within their orphanhood predicament, they continue to suffer loneliness, inferiority complex, stresses, anxieties, low self-esteem, lack of concentration in class and more negativity that militates against effective assimilation and accommodation of learning materials within their environment. The phenomenon affected both sexes and was exacerbated by poverty, need deprivation and overwhelming household and parenting responsibilities. Older OVC were contemplating dropping out of school in order to work, earn and look after their siblings. Even though some OVC reported occasional receipt of aid through donors and the government's facilities such as the Basic Education Assistance Module (BEAM), not all OVC were lucky enough to remain beneficiaries up to the end of their secondary schooling. Orphanhood was found to be a psychological deterrent to cognition and learning.
\end{abstract}

Keywords: Orphanhood, Child-headed household (CHH), Orphans and vulnerable children (OVC), Constructivist, Psychosocial, Cognition, Learning.

\section{Background}

The escalating number of orphaned children in most developing countries motivated this topical study within the area of Psychology of Education, in particular HIVIAIDS, learning and orphanhood. The orphans seem to experience many cognitive and psychosocial difficulties as they try to cope with everyday assimilation and accommodation of new schemes. Though all orphans face life crises, paternal and maternal orphans seem to be in a more favourable situation since their meta-cognition, self-esteem and self-efficacy are less affected by the orphanhood predicament. In each of the two aforementioned orphan categories, the remaining parent may still provide parental care, whereas in double orphanhood in a child-headed household (CHH) orphans and vulnerable children (OVC) look after one another.

Observations and a review of studies on orphanhood reveal that not much research has been reported in the area of the learning of OVC (Cluver and Gardiner, 2007), in particular double orphans in child-headed homes. According to Plan GDD Finland online (2005) on the impact of HIVI AIDS and CHH;

...many communities-based assistance programmes report an increase in child-headed households headed by children, or consisting only of children.

...no additional data on child headed households has yet been reported. 
The above contention implies limited research data on CHHs. Researches by stakeholders such as UNICEF tend to group together the needs of all types of OVC while there are some categories of orphans that seem to suffer more than the others. Hallman (2004) claims that the body of knowledge on OVC is beginning to grow. Observations in Zimbabwe seem to indicate that more needs to be done in research around this subject. Rigorous work on cognition and learning of double orphans from $\mathrm{CHHs}$ has not yet been fully documented, hence the need for more research activities in the area (ZNASP, 2006-2010).

Nyamukapa and Gregson (2004) cite an increase in the number of paternal, maternal and double-orphaned children as a reason for their research centred on orphanhood and primary school completion in Manicaland, Zimbabwe. The orphans were found to experience difficulties in school completion due to various factors such as poverty, lack of guidance and inability to make informed decisions at a tender age. The issue of double orphans in CHHs has led many child advocates into exploring the best ways of making parentless children cope with storms and stresses in their efforts to learn something.

Foster and William (2000) and Wood (2009, in Wood and Goba, 2011), claim that teachers struggle to balance the already challenging business of teaching disadvantaged children whose additional demands are hiked by high anxiety levels, limited concentration span, severe trauma, poverty and disease. As such, many countries in Southern Africa have developed a multi-sectoral approach to cater for such learners. It is therefore pertinent to examine the effects of double orphanhood on the learning and cognition of OVC residing in and attending school from $\mathrm{CHHs}$. If properly monitored in their parent's original homes, the OVC's ideal of remaining in their parents' homes as siblings could be an ideal psychosocial means of enhancing good learning and cognition of school tasks.

\subsection{Research Question}

What are the psychosocial experiences encountered by orphans and vulnerable children (OVC) in $\mathrm{CHHs}$ as far as their cognition and learning are concerned?

\subsection{Objective of the Study}

To determine how the psychosocial experiences encountered by orphans and vulnerable children (OVC) affect their learning and cognition.

\section{Theoretical Framework}

\subsection{Constructivism and Erikson's Psychosocial Crises}

Constructivism is a theoretical perspective that appreciates that people, including children, continue to construct knowledge as individuals, groups or societies (Donald, Lazarus and Lolwana, 2010). It challenges the positivists' traditional scientific contention that knowledge exists somewhere, that it is absolute and unchanging, and that therefore there is a need to unveil it and prove its existence. The condition of being orphaned is linked to learning and constructivism because even if children reside in awkward environments such as child-headed households, they continue to construct knowledge as they learn every day as individuals, siblings or groups. Piaget (1953) and Bruner et al. (1966), both cited in Donald et al. (2010), assert that children actively construct knowledge leading to higher levels of cognition. As such, the brain is continuously learning how to learn as it assimilates and accommodates new schemes that sensation brings about minute by minute (Piaget, 1953 in Ganga, 2011). Even if in distorted pieces, orphans continue to construct information and learn from it like any other children.

\subsection{The Psychosocial Perspective (Erik Erikson)}

Related to the interaction mentioned within the constructivists perspectives is the work of Eric Erikson, a psychoanalyst who integrated psychoanalytic perspectives with social insights and how people are active in their own development (Mwamwenda, 2004; Mangal, 2004; Sprinthall, Sprinthall \& Oja, 2006; Berk, 2007; Niolon, 2007; Berth, 2010; Chauhan, 2010). Eight stages make up Erikson`s psychosocial theory, the first five of which are featured in figure 1 below.

The authorities listed above present Erik Erikson`s (1902-1994) psychosocial stages, beginning from basic trust versus mistrust that is observed in 0-1 year olds. The stage assumes that when parents/caregivers present consistent, 
adequate and nurturing care, the child develops basic trust and realizes that people are dependable and that the world can be a safe place. The child develops a sense of hope and confidence. In cases where parents/ caregivers fail to provide basic needs, the infant develops mistrust, leading to depression, withdrawal and even paranoia (that is complete distrust) that can cause psychiatric disorder involving systematized delusion (Mangal, 2004).

The second of Erikson's stages involves autonomy versus shame and doubt. If parents guide their children gradually and firmly, and praise and accept them, independence may develop. This helps to build self-esteem up to adulthood. If caregivers become too permissive, harsh or demanding, a child may feel defeated and experience extreme shame and doubt. The child may grow to engage in neurotic attempts to try to regain control, power and competency. Ages in this stage range between 2 and 3 years.

The third stage entails initiative versus guilt. Where caregivers are supportive, the child becomes curious about people; the child shows initiative and purpose and is able to set goals that s/he will endeavour to accomplish. If punished, children tend to develop a sense of guilt that can worsen to inhibition and ruthlessness (Niolon, 2007).

The fourth stage occurs between 6-12 years and comprises industry versus inferiority. The child begins school and tries to develop competency in a number of areas. If not supported by caregivers, an inferiority complex may develop. If excessive inferiority is experienced, the child is led to helplessness and inertia (Niolon, 2007). The stages up to this level tend to discover the child's world or environment whilst the next four stages try to understand the self.

Berk (2007) and Sprinthall et al. (2006) posit that according to Erikson, identity versus role confusion falls within ages 13-19 years or adolescence. The young adults may become more involved in their sexual identity and gender roles. They can even try learning different roles, may go through an identity crisis, and can sometimes use their friends to reflect back on themselves. If the adolescents succeed in resolving the life crisis, they may develop fidelity, which is the ability to be true to something, to devote oneself unconditionally to a worthwhile purpose, but if they fail to resolve the crisis, they may develop identity diffusion where their sense of self is unstable and threatened. This and the other stages mentioned above are areas where the defined child or OVC in this enquiry is placed.

The sixth stage covers intimacy versus isolation, between 20-24 years. The stage involves identity development and the virtue gained is usually intimate love. According to Niolon (2007), failure to develop intimacy with the opposite sex may lead to promiscuity. In Chauhan (2010), creativity versus stagnation marks the seventh of Erikson's stages in the age range 25-64. The adult is concerned about the next generation and care for family life and other people. The opposite of generativity is stagnation, where one may become self-absorbed which, if extended, may lead to selfrejection or failure to afford time for oneself.

The final stage is ego integrity versus despair (65 to end of life span). In concurrence with Chauhan (2010), Berth (2010) contends that in ego integrity, many people may tend to accept their life successes and may develop a sense of wisdom. The opposite is a feeling of despair and dread of death, yet it may be too late to change their lives. Too much integrity may lead to presumption whilst too much despair leads to disdain for life (Niolon, 2007).

Erikson's (1968) theory covers a whole life-span and it is prudent to discuss the theory from stage one up to stage eight because, as a psychoanalyst, Erikson agreed with Freud that early life experiences may shape the later life personalities. Therefore, studying the whole life span may also alert adults/caregivers to their roles in the care of OVC, even if they view them in their CHHs. This study's population and sample of children is concentrated on the first five stages as part of the theoretical framework because the researchers delimited the definition of the child or OVC in the $\mathrm{CHH}$ between age 18 and below. Even if the theory does not directly focus on cognitive development, it helps to explain and interpret the OVC's developmental experiences within their CHHs through socialization and how this may affect their sense of self.

Within the psychosocial stages of development are life crises that relate to people's emotional needs and social interactions (Berk, 2007). Just like all other persons, the OVC face critical life challenges or crises in their lives. How each one of the children resolves these life conflicts may certainly affect their cognitive functions. The manner in which the OVC resolves each challenge has a bearing on upcoming challenges. For instance, an OVC who has learnt not to trust his/her environment due to previously experienced sexual abuse might find himself/herself continuing to doubt the environment at a later stage of life, for instance adolescence.

Donald et al. (2010) reiterate the fact that people`s capacity to confront their psychosocial challenges throughout life, and to modify and develop the way they worked on them originally, is characteristic of Erikson`s viewpoint. All people have positive and negative life experiences._The challenge for OVC is how to best resolve life tensions and challenging experiences, especially where the experiences may result in developmental problems such as learning difficulties. Figure 1 (appendix A) provides a diagrammatic representation of Erikson`s psychosocial theory and how the first five crises can militate against effective learning and cognition of parentless children living as siblings in $\mathrm{CHHs}$. The numbered boxes on 
the left symbolize a normal child's environment, while those on to the right reflect life experiences of OVC in CHHs.

Figure 1 (appendix A) presents the first five of the eight psychosocial conflicts in a normal home (Berk, 2007), whilst juxtaposing these with a possible situation in a $\mathrm{CHH}$. The selected five stages demarcate the boundaries of the study where the researchers have defined a child up to the age of 18 years. The rest of the psychosocial stages are shown in the diagrammatic representation but are vital for understanding the implications on learning, as well as the cognitive and later development of children reared by other children. The study accepts the psychoanalytic fact that early experiences have a bearing on later life personalities (Meyer, Moore \& Viljoen, 2006; Bee, 2007).

Within Erikson`s psychosocial development theory, infants from birth are usually dependent on their caregivers for all nurturance and care (Ormrod, 2000). Misfortunes such as parental death or a caregiver's death bring about change in the environmental experiences for the infant. The sudden change of environment brought about by parental death results in changes and unpredictable life experiences. Whilst infants with parents in a normal family environment may experience quality of life and learning, the infant $\mathrm{OVC}$ in a $\mathrm{CHH}$ usually experiences the opposite. In other words, learning and cognition take place in difficult life circumstances.

The infant trusting the environment because of proper care-giving from parents usually prepares for the next stage with hope and confidence, whilst the OVC may remain anxious and may not trust the future. Other variables may also reinforce either negative or positive psychosocial experiences in the inexperienced child parent. The particular lot of OVC in Zimbabwe, where this study was carried out, is seen both in rural as well as urban dwellings. Each set of circumstances may influence the learning and cognition in a particular way.

At stage two (autonomy versus shame and doubt), a toddler experiences psychosocial crises linked to attachment with peers, siblings and some role models (Berk, 2007). In a normal home a child experiences some independence as s/he starts to move around the home. S/he may cope in a normal home because of gentle encouragement (Darling and Steinberg, 2004), whilst one in a $\mathrm{CHH}$ might experience inconsistencies or maltreatment from the inexperienced child parents. The manner in which s/he is encouraged or discouraged may enhance autonomy or induce shame and doubt coupled with anxiety carried over into mistrust of the environment from infancy (Mangal, 2004).

In the third stage, early childhood, the child experiences imitativeness versus guilt orientation (Ormrod, 2000). In a normal home, the child explores with the aid of parental guidance and the rest of family members, whereas in a $\mathrm{CHH}$ the infant might ask questions whose answers no other sibling is able to give because of inexperience. In the $\mathrm{CHH}$, age counts. The older a sibling is, the better the listening capacity one receives from the other children. The child may try out things and fail and feel guilty or pass and feel contented. A child`s status at this level usually enables him/her to feel a sense of purpose and continue being inquisitive or, due to anxiety and lack of encouragement, s/he may feel guilty all the time and may not want to try out anything new. Such children are sometimes reserved, isolated and may not want to be involved in tackling anything new.

As the child grows older in the fourth stage of industry versus inferiority (middle childhood), s/he is ripe for school or is beginning to be productive depending, on his/her social context (Berk, 2007). The one in a normal home begins social relations with a mother, father, siblings, members of the extended family as well as peers and teachers. The double OVC begins his/her social interactions from siblings and extends relationships to other relatives, peers and teachers, if they are lucky enough to be in school. A sense of industry results from success in a number of tasks whilst failure brings about feelings of inferiority. Erikson believed that the child carries either competence or lack of it, depending on their socio-economic status. OVC in poverty-stricken $\mathrm{CHH}$ are sometimes faced with continual failure due to ridicule from siblings or their inexperienced child-parents. Failure deters learning and cognition (Jinga and Ganga, 2011).

The fifth of Erikson`s stages that rounds off childhood before entry into adulthood is identity versus role confusion, which is experienced by the adolescent. Research has shown that in $\mathrm{CHH}$ the older adolescent usually takes the place of the caregiver, whose duties are those of a mother and/or a father (Lewis, 2000; UNICEF, 2001; Ward and Eyber, 2009). Most of the time the central challenge is to balance the role of a child with the extra role of being a child-parent. In both $\mathrm{CHH}$ and normal families, the adolescent faces stresses from physical maturation, fitting into or dealing with peer groups (peer pressure) and making lasting friends. They wonder who they are and what particular place they should take within their environment. The major burden on the OVC in $\mathrm{CHH}$ is how to be 'a good big brother' or a 'good big sister' to the rest of the siblings. No matter what their socio-economic status, all adolescents search seriously for identity, either as individuals or as groups. In the school environment, the teacher becomes a powerful role model and so is encouraged to be empathetic with all learners.

If the life crises are fully or adequately resolved at each stage, then the child might be able to enter into adulthood and move through the sixth, seventh and eighth stages without too many difficulties. Erikson`s theory is significant as 
part of the theoretical framework in this study, for it specifies the experience that some children go through and how each child experiences the impact on their development. The plight of the OVC in the $\mathrm{CHH}$ observed in this study requires serious consideration from any OVC advocate. The child's psychological and social development centres on proper parental guidance without which development and learning can sometimes be distorted. Double orphanhood represents one variable that can bring about constraints in learning and within social settings.

The theory is also significant in that Erikson, in this study, sees people, including OVC, as active in their development. Irrespective of the nature of the crises or the intensity of their orphanhood, the theory believes that children are able to modify and handle challenges the best possible way. To enhance learning and cognition of the double orphans discussed in this study, an educator needs to create opportunities for the OVC to explore and confront any psychosocial challenges that might come their way. Unlike Piaget and Vygotsky, who dealt mainly with cognition, Erikson argues for an interdependence of different life aspects (Ormrod, 2000; Driscoll, 2009; Cole, Cole \& Lightfoot, 2009) that can affect learning.

Erikson regards cognitive, emotional, social, physical, moral and spiritual aspects of development as integrated variables in the whole life cycle (Niolon, 2007). Even if this study tries to search for learning and cognition alone, it is vital that the whole child or whole OVC is dealt with fully so that any obstacles that may hinder cognition and proper learning are incorporated in all efforts to assist children living in difficult life circumstances.

\section{Research Methodology}

\subsection{Ethical considerations}

The major concern of this study was to construct social reality on the psychosocial encounters of OVC in child-headed households. This was a sensitive study; hence a number of ethical considerations took precedence in order to safeguard the orphaned and vulnerable children, the researcher, the teachers, as well as the government and non-governmental stakeholders involved. The ethical considerations included issues of confidentiality, autonomy, beneficence and nonmaleficence of human research participants as stipulated in the UNISA Policy on Research Ethics (2007).

The status of the major participants, which was orphanhood, raised attitudinal fears that would have inhibited orphans from becoming participants in this study. An effort was made to allow the participants to go through some individual and group psychosocial counselling where the major purpose of the study was explained. The issue of signed consent and assent forms remained vital from the beginning.

\subsection{The Research Design}

This study fell within a qualitative research paradigm. The researchers employed a phenomenological descriptive case study. The major intention in phenomenology is to comprehend the phenomena through descriptions by the human subjects of their conscious, social experiences (Creswell, 2007). In this case, the OVC in CHHs were encouraged to tell about their experiences as far as cognition and learning were concerned. The teachers and headmasters working with the OVC most of the time assisted in observations that aimed to authenticate learning experiences presented by the OVC.

As guided by Schram (2006) and Yin (2003), the case study design has the ability to adapt to a wide range of frameworks, such as phenomenology, in which it strives to describe, analyse and interpret the psychosocial crises that affect the learning and cognition of OVC in $\mathrm{CHHs}$. In this case study, we endeavoured to explore and present descriptions of authentic situations in the developmental and learning experiences of OVC. The study comprised an exploration of a bound system involving multiple cases over a given period through detailed, in-depth data collection by means of multiple sources of information from varied data collection tools as well as the purposefully selected participants (Creswell, 2007).

\subsection{Sampling the participants}

Four secondary schools were purposefully selected because it had been noted that a large number of the OVC found in the schools were attending school from child-headed households. In each of the four schools (two rural and two urban); five double orphans (making a total of 20), the school principal (four in all), two teachers (eight in all), one District Education Officer and a Social Welfare Officer were purposively selected to make a total sample of 34 participants. The 
idea of purposeful sampling was to obtain the most characteristic representation of attributes that served the purpose of the study (Grinnell and Unrau, 2008). The sample in this qualitative case study, 34 participants, was small and mainly designed to allow participants to relate their life experiences (Rubin and Babbie, 2008).

\subsection{Data collection}

Prior to visiting the schools and $\mathrm{CHHs}$, the researchers obtained permission to do research in the Chipinge district. Some senior members of the government of Zimbabwe's (GoZ) ministries had to be consulted. After having obtained research permission and consent from the Chipinge District Administrator at the Chipinge Local Government Offices, the researchers also sought consent from the Secretary of the Ministry of Education, Sport, Art and Culture (MoEASC) at the Zimbabwe MoEASC head-office, the Education Director at the provincial office as well as the Education Officers at the MoEASC Chipinge district offices. The permission was granted without any challenges.

Numbered alphabet codes were used to identify each of the 34 participants at each data collection venue. Openended questionnaires and interviews, focus group discussions and observations were used to collect the required data regarding the psychosocial and learning experiences of OVC living in $\mathrm{CHHs}$.

\subsection{Data analysis plan}

For data analysis, the thematic procedures (O'Neill, 2011), involving cross tabulations, descriptions, narratives, anecdotal records, vignettes and other manual procedures were augmented by the use of the qualitative data analysis tool coined by Tesch (1990) in Creswell (2002). These procedures occurred simultaneously with data collection and interpretation (Creswell). This led to the reduction of the data and the creation of particular codes and clues for themes to follow in presenting the qualitative findings.

\section{Research Findings}

Fifteen (15) OVC (i.e. BR6 -DR20) belonged to rural secondary schools while five (5) OVC (AU1-AU5) belonged to urban secondary schools. All the (20) OVC were literate and attending school (forms 2-5) within their locality. Most of their parents had some liabilities and had left no significant assets for their children except for either a 2-4 roomed house or hut(s). Codes AUS21 up to DRS32, US33 and US34 were pseudonyms for the14 stakeholders involved.

\subsection{The psychosocial encounters of OVC in and outside class}

The findings corresponded with Erikson's psychological stages as explained by other constructivist theorists (Niolon, 2007; Berth, 2010; Chauhan, 2010). The OVC seemed to be holding on to unresolved life crises, ranging from a lack of or occasional trust to role and identity confusion in the adolescent OVC who were the major participants in the enquiry. In some instances the adolescents succeeded in resolving their life crises, yet in most cases they suffered identity diffusion, a lack of stability and feelings of being threatened by life encounters that were ruled by both rational to irrational childhood experiences.

Perhaps by delving into the children's real voices or developmental stories, we can help readers of this study to find ways of helping the parentless child. On one positive note, one OVC (AU2) from an urban $\mathrm{CHH}$ of Chipinge narrated what we called 'urban positives'. He explained:

I am treated well, like a child of their own. There are no negative effects on my learning though sometimes I wish if my parents were alive to see my progress in school. I take adequate food at 1-0-1 which is a normal trend in our locations. However, the issue of late payment of school fees also affects me. Though I receive adequate food, my relatives always take time to decide to sell my parent's stock in our rural home for my fees, citing the fact that the whole chain of relatives or extended family members should be notified and agree first. Unfortunately, culture stipulates that children may not make major decisions to sell properties without the consent of elder members of extended family.

The repercussions of such a finding were that even though some children were living comfortably in their $\mathrm{CHHs}$, they were not free to make decisions as they saw fit. Such an ecological developmental experience may eventually penetrate into problems of cognitive conflicts even if the OVC was gifted and eager to progress with learning.

Sentiments expressed by both rural and urban learners indicated that the OVC could be living with many 
psychosocial challenges that affected their cognitive learning process as they tried to assimilate and accommodate what the learning environment provided. Some statements expressed by learners showed that not all the children in the $\mathrm{CHH}$ were receiving adequate parental nurturing that could enable them to learn to trust their environment as a learning base.

As far as learning was concerned, the boys and girls seemed not to be fully prepared for the parenting roles that they became engaged in when they opted to reside in $\mathrm{CHHs}$. Circumstances beyond their control pushed them into adult roles that forced them to assume greater responsibility than what available resources allowed. This finding was consistent with many of the studies reported in the literature on CHHs (UNICEF, 2009). As a result of the exaggerated roles, the children's education was affected, resulting in a negative impact on the learner's mental health. The psychological encounters were aggravated by incidences of stigma and discrimination from various quarters of their proximal relationships, including extended family members, peers and neighbours.

\subsection{Threats to drop out of school}

The 20 children that we interviewed mentioned the fact that the first and foremost psychological problem faced by the OVC was continued absenteeism that eventually resulted in dropping out of school. They narrated their ordeal but were even much more concerned about those OVC that had already dropped out of school and were engaged in very hard physical work as farm labourers, housemaids and options that are even more difficult. Nyamukapa and Gregson (2004) also note the issue of OVC school dropouts. Because the children had to earn and learn, they then received marginal or no help at all from their extended family, whom they accused of greater stigmatisation and discrimination. Some had to work in the fields before school each day. They were accused of dishonouring the norms and values prescribed by culture in which extended family members should oversee the welfare of the deceased's children. The decision to reside without interference from the members of the extended family placed them in recurring situations of neglect from their relatives. Therefore, managing household chores and learning at the same time still seemed a better option but the children were unsettled psychologically.

We endeavour to demonstrate here the status of the children whose formal learning was swiftly coming to a standstill because facilities in most of the $\mathrm{CHHs}$ seemed not to allow learning to continue.

Figure 2 reveals that of the twenty OVC in the study, 16 could be out of school by year-end if no immediate intervention was found. Asked about BEAM funding, the OVC involved in the focus group discussion concurred that sometimes the funds were not available for all. One could have fees paid over one term while the rest of the terms were not funded. The finding was in agreement with research findings in which an NAC officer hinted that the BEAM funding was overwhelmed (NAC, 2011) because the number of OVC needing aid was very high.

\subsection{Loneliness affects learning}

The majority of the children interviewed were not treated so badly and stigma had decreased due to awareness campaigns especially from the various government ministries and NGOs within the district. Many people now knew and understood the fact that the rising number of OVC was due to lack of cure for the commonest cause of parental death, namely HIVIAIDS. However, the children complained of loneliness. Below is a list of statements from the focus group discussions as the OVC (AU5, BR6, BR10, CR13, CR15, DR16, and DR20) interacted on the issue of learning and loneliness.

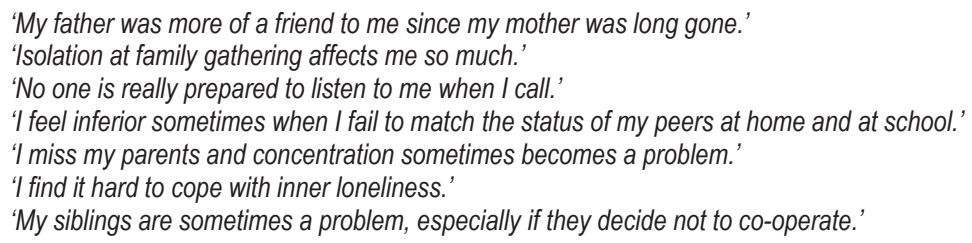

It was however pleasing to note that the children appreciated the fact that some of their peers empathized with them and were always ready to assist with books and any necessary scaffolding in the learning process. 


\title{
4.4 Some responsibilities lead to psychosocial problems
}

All the children faced responsibilities where they indicated that many thoughts led to distress. The thoughts of responsibilities tended to overpower learning thoughts. A 15-year-old OVC (BR10) narrated such issues as:

\begin{abstract}
Kufunga kuti nhasi ndodyei (The thought that I need to look for food), is a problem on its own. It becomes worse when I also need to look for not only my food but that of my little brothers and sisters. I spend time worrying about how to make them happy. When they fall sick, I fail to attend school because if I do, I find it difficult to concentrate. Our aunts do not feel comfortable to leave their homes in order to come and take care of the sick. There is just too much work at home and I have no reading time.
\end{abstract}

Having too many household chores interfered with the learners' cognition activities so much that many of the OVC concurred that leaving school was a better option. If, on the other hand, the proper strategies to assist the real needy cases could be established, the community could liberate the suffering child. In some countries, societies have opted for institutionalization and foster homes with adult caregivers (HIVIAIDS Alliance, 2006), while others such as the Islamic minor child only become orphaned upon the death of the father, not the mother. These literature clues can help in charting the way forward for the local OVC.

\subsection{Abuse and neglect}

Some children reported abuse and neglect by their extended family overseers. It was sad to note that while the children suffered so much financially, they were totally unaware of some assets that some of their parents had left behind for them. What they inherited as surprises were sometimes the hospital bills or balances of loans taken out by their parents, so much so that what their parents used to own was usually sold in order to settle the bills before the OVC's school fees and general welfare were considered by the $\mathrm{CHH}$ extended family overseers. They mentioned the fact that what extended families did best was to help locate 'piece jobs' for the older OVC, especially if they failed to get social welfare and NGO support.

In other situations, children complained of some community members who exploited the children's lack of security and chose to steal from them at night because they were unable to get out into the dark to chase the thieves. The community was reported to be turning a blind eye toward such criminal acts, as was narrated by CR14:

\begin{abstract}
We hear our ducks quack, chickens cluck and goats bleat but we are unable to help it. We cannot follow the thief; because we are too young and afraid of the unknown. If at all people would desist from stealing the little we have left, we would then have a starting point. As a result, we sometimes try to beg but not much comes out of the trouble that begging from other citizens entails.
\end{abstract}

The children also reported that there were no sexual abuses but neglect by locals and extended family members. A female child-head (DR17) explained:

\begin{abstract}
'Uncle had promised to pay my fees but whenever I asked; he mentions other silly issues to disrupt the request. No one seems to notice when we complain. Other women in the society accuse me of prostitution especially when I happen to purchase anything nice from the local shops. They really want to know the source of the money because they feel orphans do not have money for luxuries such as a full chicken for our household meal. We are invited by most of the local elite to work a lot in their gardens and fields but for very little payment. Perhaps my parents should have remained living until we become much older.
\end{abstract}

All these psychological problems filtered into the young minds and resultantly had a negative impact on their learning and cognition.

The data reported so far has provided evidence that when parents die, some OVC develop helplessness over time. They then became angry, bitter, frustrated, and sometimes feel unnecessarily guilty (Erikson, 1968 in Woolfolk, 2004; Niolon, 2007) because they believe that their parents died too soon. We observed a great deal of tension and lack of inner peace in the learners as we interacted with them. The children no longer behaved like children, as they took up household responsibilities without adult guidance. Some OVC had developed anger over their relatives and some community members, blaming them for initiating home treatments and conditions within the extended family homes that ended up driving OVC off into $\mathrm{CHHs}$.

The excerpts, when fully scrutinized, seemed to indicate the fact that the children felt insecure and longed for 
parental love and affection. They were all grateful for the interviews and the fact that the researchers seemed to show great concern over them. Problems such as illnesses, familial deaths, as well as negative attitudes of some relatives and neighbours all created a harmful impact on the psychological well-being of orphaned children in $\mathrm{CHHs}$. We noted the 'why me phase' in three quarters of the OVC who were surviving under difficult life circumstances. Some manifested early signs of depression which most of their teachers had noted over time during lessons and even outside classes. In fact, the poor OVC manifested feelings of inferiority that seemed to be leading them to feelings of hopelessness and inertia that many of them tried to cope with. Perhaps the adolescent stage in which these children found themselves confused them further as they tried out different roles and experienced identity crises. According to Erikson in Woolfolk (2004), when adolescents succeed in resolving crises, they develop fidelity. Society needs to scrutinize the OVC issues in which these children had, in most cases, failed to resolve their life crisis and had developed identity diffusion where the sense of the 'self' seemed to be unstable and threatened (Erikson). The portion of Erikson's work within the theoretical framework indicates the OVC situation juxtaposed to a normalized family situations (see figure 1). Society needs to examine the orphan crises that seem to have detrimental effects on the cognition and learning of children from childheaded households.

\section{Recommendations}

Teachers are encouraged to extend their loco-parentis duties to weekends and vacations in order to afford each learner the care and support that s/he continuously requires and searches for. Looking at the high poverty levels in CHHs, policymakers should establish ways of controlling or eradicating the tuition fees for those that are incapacitated due to poverty. The children should receive the necessary support in order to stay in school. Educators should be empathetic enough to give the OVC free academic assistance even during the vacations and weekends.

Maintaining all children in school is an important intervention in several ways. It retains children's connectedness to peers, familiar adults and to an institutional identity. Schooling provides children and society with future knowledge and skills. Keeping children in school could also help to prevent vulnerability to HIV infection, by protecting children and reducing the child's need to seek shelter, food and clothing through risky encounters with unscrupulous adults. In fact, schools should become sustainable learning environments for all minors including the OVC (Mahlomaholo, 2011).

All stakeholders such as heads, teachers, DEOs and SWO should mobilize NGOs working with OVC to give academic aid in the form of stationery, fees and uniforms in addition to the food rations that they normally give to the marginalized.

It is vital that investigations be carried out with children in order to find the best alternatives to the biological family. Perhaps cooperative research could be conducted on existing children's homes countrywide where foster parents substitute the biological parent and the life in $\mathrm{CHHs}$. There could be a monitoring mechanism for events in the $\mathrm{CHHs}$ so that the real needy areas could be addressed before well-wishers flood the $\mathrm{CHHs}$ with goods that may not be needed at a particular time.

Very often, university academics, researchers, governments, civil societies and other well-wishers recommend intervention programmes for marginalised groups yet implementation may not take off or remain at pilot level, resulting in the intended beneficiaries continuing to suffer within their micro to macro system interactions. More of action research projects are encouraged to help the child in need. It may be necessary to place the OVC issue on a high research agenda as was initiated in Rwanda and Kenya.

The GoZ could try to empower the OVC through free education from AIDS levies, especially for double orphans, so that the children may realize their life goals. Learning should be freely available to the double OVC up to university level. Teach the OVC skills for survival for purposes of sustainability. Rationing could be phased out by 'teaching the children how to fish instead of giving them fish every day', as the saying goes.

\section{Conclusions}

The ecological impact of child-parenting in poorer situations seems to be much more detrimental than helpful because the children's anecdotal reports and observations noted instances of need deprivation in various formats. Therefore, educators have a role to play in the dismantling oppression of children (Francis and Roux, 2011) and generating a vision for creating a more socially just future for the OVC.

The findings seem to depict the fact that many areas of an OVC's cognitive learning seem to be desperately interfered with as the child continues to face challenges surrounding being parentless and residing in a child-headed 
household. Each of the areas of learning is significantly affected because of the OVC's inability to procure adequate learning resources, especially the recurring issue of lack of fees, stationery, uniforms, etc. The OVC's display of learning difficulties, especially due to lack of resources, seems to be congruent with findings in a number of studies on children's experiences in $\mathrm{CHHs}$ in developing countries such as Rwanda and South Africa. The state of affairs leaves the OVC in a desperate situation that eventually culminates in cognition and learning defects as was unpacked by the twenty OVC. The fact that all the consulted stakeholders confirmed instances of disruptions of a child's concentration span and formulation of schemes, confirms that many of the OVC are surviving in very difficult life circumstances that require every stakeholder's intervention if care and support mentioned in Millenium Developmental Goals (MDG 6) is to be fully realized by every OVC. The despondency expressed by three quarters of the children over their inability to access full opportunities to stay in class affects all stakeholders, bearing in mind the fact that the attainment of all EFA goals is the responsibility of all citizens of a country, and especially of the government, non-governmental and civic organizations that advocate the rights of all children.

Orphanhood disrupts information processing (Atkinson and Shifflin in Kosslyn and Rosenberg, 2008), thus confirming the OVC's plea that they need assistance to enable them to learn. As such all learning, be it latent, insight, situated, cooperative, or mastery, is significantly affected by orphan crises, as is evidenced by the meanings that one can construe from the various anecdotal excerpts in which both OVC and stakeholders narrated the OVC ordeal and how it infringes on the cognition and learning of the OVC. It is also possible that the storms and stresses (Erikson's theory) that the OVC continue to face as adolescents may not only affect learning and cognition per se, but may filter into their ecological environment (Bronfenbrenner, 2008). This denotes the fact that the present difficulties faced by the OVC may not be their problem alone but may affect every citizen because eventually the effects may catch up with every Zimbabwean, bearing in mind the fact that Ubuntu, Ubuntu ngaBantu ('a person is a person because of people').

The implication, therefore, is that as the double OVC try to construct knowledge in and outside class, they will require aid in various formats if they are to enjoy their right to quality learning. Though they may want to remain resilient to the orphan crisis, they seem to be surviving in a hazardous environment that carries with it a number of risk factors (Rutter, 2005) that are evident now and may hold far-reaching repercussions for the individual and his /her ecological environment as s/he grows into adulthood. Therefore, Rutter's idea of shaping a positive life-line (Rutter in Ganga and Chinyoka , 2010) for OVC is indeed aligned to Mandela's contention that there can be no keener revelation of society's soul than the way in which it treats its children (Mandela in NAP Child-Friendly version, 2006-2010:1) There is a need for provision of parenting education to all child-parents and care-givers in order to enhance the academic and social performance of at-risk children. Improved parenting can lead to better child outcomes, but only if other needs in a family's life are also addressed.

\section{Acknowledgements}

We gratefully acknowledge the following groups and individuals who offered their consent and/or assent to participate in the research process: the Zimbabwe Ministry of Education, Sport, Art and Culture (from head office, through provincial office to district office up to the selected schools), the Chipinge District Administrator's office, extended family members responsible for overseeing activities within the child-headed households, and the orphans and vulnerable children involved in this enquiry.

\section{References}

Bee, H. 2007. The developing child. New York: Harper and Row Inc.

Berk, LE. 2007. Development throughout the lifespan. Boston, New York, San Francisco: Pearson, Ally and Bacon.

Berth, LE. 2010. Child development. 3rd ed. Boston: Allyn and Bacon.

Bronfenbrenner, U. 1979. In Oswalt, A. 2008. Urie Bronfenbrenner and Child Development on Mental help. [Online]. Available at: http://www.mentalhelp.net/poc/view-doc. [Accessed on 23 March, 2011].

Chauhan, SS. 2010. Advanced educational psychology. New Dehli: Vikas Publishing House.

Chinyoka, K. \& Ganga, E. 2011. An exploration of psychological effects of poverty on child development in Ngundu in Zimbabwe. NAWA Journal of Language and Communication 4(1): 143-466.

Chirwa, WC. 2002. Social exclusion and inclusion: challenges to orphan care in Malawi. Nordic Journal of African Studies, 11(2):93-103.

Cluver, L. \& Gardiner, F. 2007. Risk and protective factors for psychological well being of children orphaned by AIDS in Cape Town: a qualitative study of children and caregiver perspectives. AIDS Care, 19(3): 318-325.

Cole, M., Cole, S. \& Lightfoot, C. 2009. The development of children. 6th ed. New York: Worth Publishers.

Creswell, JW. 2007. Qualitative inquiry and research design: choosing among five approaches London: SAGE. 
Darling, P. \& Steinberg, LD. 2004. Parenting styles and contexts: an integrative model. Psychological Bulletin, 113(3): 487-496.

Donald, D., Lazarus, S. \& Lolwana, P. 2010. Educational psychology in social context: ecosystem application in South Africa. Cape Town: Oxford University Press.

Driscoll, MP. 2009. Psychology of learning for instruction. 2nd ed. Acedham Heights, M.A: Ally and Bacon.

Erikson, E. 1968. In Niolon, R. 2007. Erikson's psychosocial stages of development. [Online]. Available at: http://www.psychpage.com/learning/library/erikson.html. [Accessed on 27 July, 2011].

Foster, G. \& William, J. 2000. A review of current literature on the impact of HIVIAIDS on children in Sub-Saharan Africa. AIDS 2000. 14(Suppl. 3): 275-284.

Francis, D. \& Roux, A. 2011. Teaching for social justice education: the intersection between identity, critical agency and social justice education. South African Journal of Education, 31(3): 299-311.

Ganga, E. 2011. Influence of environmental variables on learners' cognitive performance; the case of Mutare. Berlin: Lap-Publishers.

Ganga, E. \& Chinyoka, K. 2010. Psychological disorders caused by poverty among orphans and vulnerable children in child headed households in Zimbabwe, Journal of Sustainable Development, 12(4): 186-196.

Grinnell, RM. \& Unrau, YA. 2008. Social work research and evaluation: quantitative \& qualitative approaches. $7^{\text {th }}$ ed. New York: Oxford University Press.

Hallman, K. 2004. Socioeconomic disadvantage and unsafe sexual behaviours of young women and man in South Africa. Policy Research Division Working Paper No 190. New York: Population Council. [Online]. Available at: http://www.popcouncil.org/publications/wp/wplist.html. . [Accessed on 27 July, 2011]

HIVIAIDS ALLIANCE, 2006. A situational analysis of child-headed households and community foster care in Tamil Nadu and Andhra Pradesh States, India. New Delhi: International HIVIAIDS Alliance.

Jinga, N. \& Ganga, E. 2011. Effects of holiday lessons and financial pressure on low income families and households in Masvingo, Zimbabwe. Journal of Emerging Trends in Educational Research and Policy Studies (JETERAPS), 2(6): 465-470.

Kosslyn, SM. \& Rosenberg, RS. 2008. Psychology in context. New Delhi: Pearson Education.

Lewis, JC. 2000. Orphanhood prevalence in rural Zimbabwe. Dissertation submitted for MSc in Applied Statistics. University of Oxford, United Kingdom.

Mahlomaholo, MG. 2011. Gender differentials and sustainable learning environments. South African Journal of Education, 31(3): 312321.

Mangal, SK. 2004. Advanced educational psychology. New Delhi: Ph Learning Ltd.

Meyer, WF., Moore, C. \& Viljoen, HG. 2003. Personology: from individual to ecosystem. Johannesburg: Heinemann.

Mogotlane, SM., Chauke, MC., Van Rensburg, GH., Human, SP. \& Kganakga, CM. 2010. Child-headed households. Curationis, 33(3): 24-32.

Mwamwenda, TS. 2004. Educational psychology: an African perspective. $2^{\text {nd }}$ ed. Durban: Butterworth.

National Action Plan (NAP) for orphans and vulnerable children: child friendly version 2006-2010. Harare: Government of Zimbabwe.

Niolon, R. 2007. Erikson's psychosocial stages of development. [Online]. Available at: http://www.psychpage.com/learning/library lerikson.html. [Accessed on 20 March, 2011].

Nyamukapa, C. \& Gregson, S. 2004. Extended families and woman's roles in safeguarding orphans' education in AIDS-afflicted rural Zimbabwe. Social Science and Medicine, 60(10): 2155-2167.

O`Neil, V. 2011. Psychology: an introduction. $3^{\text {rd }}$ ed. Cape Town: Oxford University Press Southern Africa.

Ormrod, JE. 2000. Educational psychology: developing learners. Sydney: Prentice Hall.

Plan GDD Finland. 2005. [Online] Available at: http://www.orin.org/docs/resources/ treaties/coc.40D/GDD 2005 Plan Finland.pdf. [Accessed on 2 February, 2011].

Rubin, A. \& Babbie, ER. 2010. Research methodology for social work. $6^{\text {th }}$ ed. Belmont, CA: Thomson Brookes/Cole.

Rutter, M. 2005. How the environment affects mental health. The British Journal of Psychiatry, 186(January): 4-6.

Schram, TH. 2006. Conceptualizing and proposing qualitative research. $2^{\text {nd }}$ ed. Upper Saddle River, NJ: Pearson Education.

Sprinthall, NA. Sprinthall, RC. \& Oja, SN. 2006. Educational psychology: a developmental approach. $6^{\text {th }}$ ed. New York: McGraw-Hill.

UNICEF, 2009. Promoting quality education for orphans and vulnerable children: a sourcebook of programme experiences in Eastern and Southern Africa. New York: UNICEF.

UNISA Policy on Research Ethics, 2007. Pretoria: UNISA.

Venter, E. \& Rambau, E. 2011. The effect of a latchkey situation on a child`s educational success. South African Journal of Education, 31(3): 345-356.

Ward, LM. \& Eyber, C. 2009. Resiliency of children in child-headed households in Rwanda: implications for community based psychosocial interventions. Intervention: The International Journal of Mental Health, Psychosocial Work and Counselling in Areas of Armed Conflict, 7(1): 17-33.

Wood, L. \& Goba, L. 2011. Care and support of orphaned children at school: helping teachers to respond. South African Journal of Education (SAJE), 31: 275-29.

Woolfolk, A. 2004. Educational psychology. 9th ed. New Delhi: Pearson Education.

Zimbabwe National AIDS Council NAC, 2011. [Online]. Available at: http://www.infsw.org/p3000535.html. [Accessed on 25 January, 2011].

Zimbabwe National HIV and AIDS Strategic Plan (ZNASP), 2006-2010. National AIDS Council, Harare: Government Printers.

Zimbabwe National Orphan Care Policy (ZNOCP), 1999. Harare: Government Printers. 


\section{Appendices}

\section{Appendix A}

Fig. 1. Erik Erikson's first five psychosocial developmental crises in a normal family, with parental support juxtaposed to a parentless $\mathrm{CHH}$ situation (stages adapted from Berk, 2007)

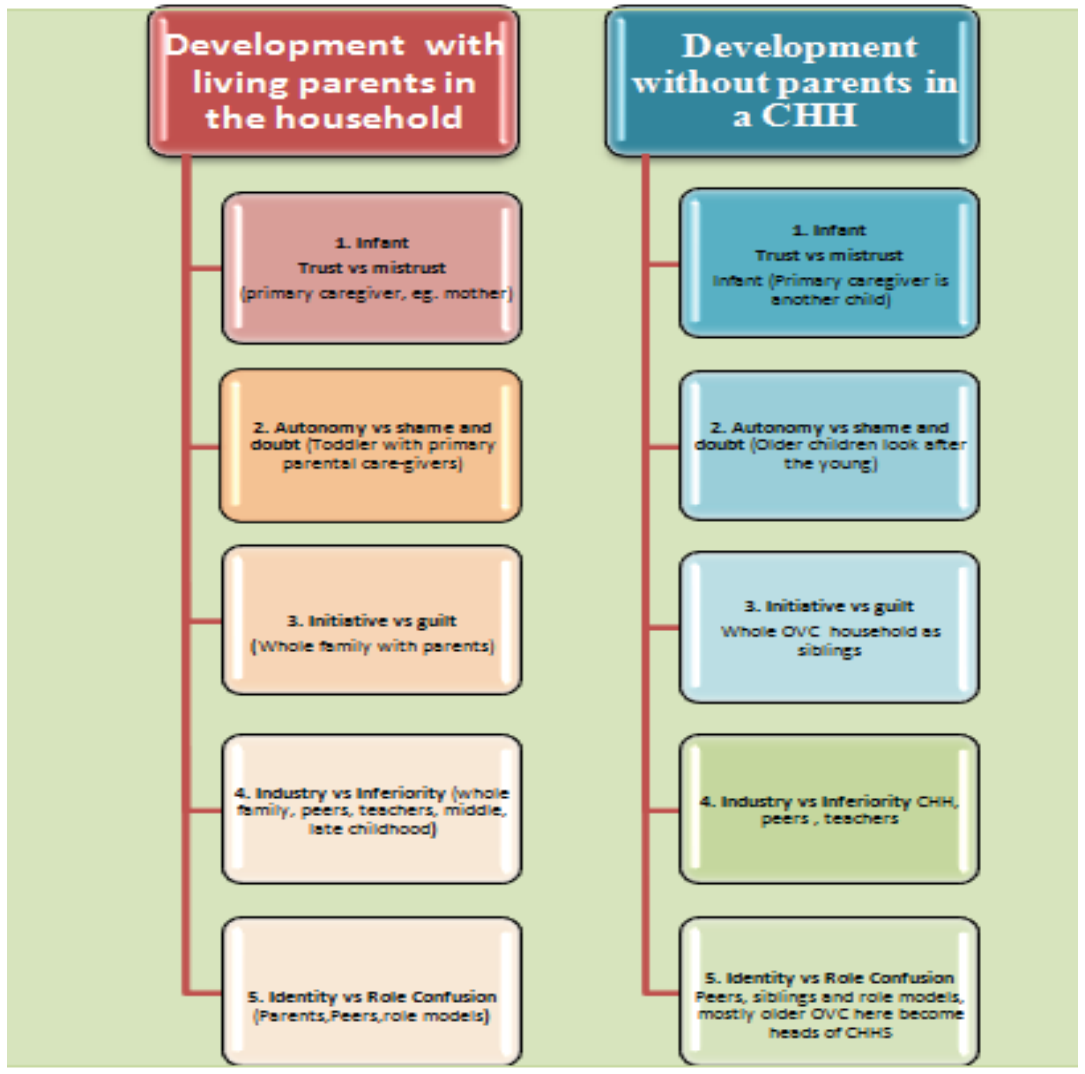




\section{Appendix B}

Fig. 2. Pie Chart showing OVC threatening to drop out of school due to lack of sufficient support.

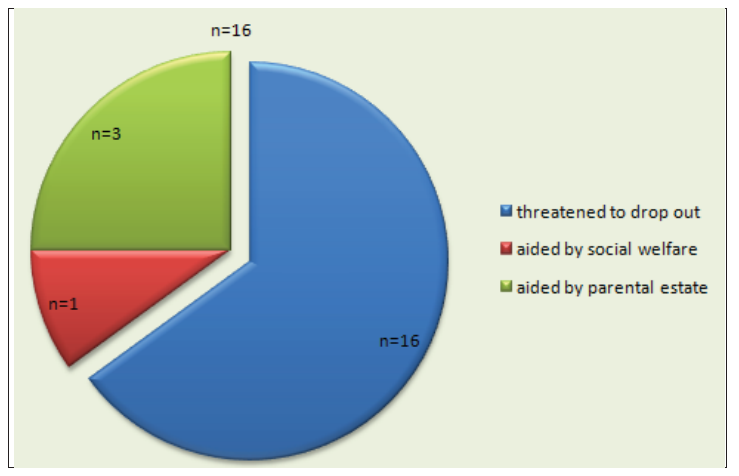

\section{Appendix C}

\section{Acronyms}

$\begin{array}{ll}\text { BEAM } & \text { Basic Education Assistance Module } \\ \text { CHH } & \text { Child-Headed Household } \\ \text { DEO } & \text { District Education } \\ \text { EFA } & \text { Education for All } \\ \text { GOZ } & \text { Government of Zimbabwe } \\ \text { HIVIAIDS } & \text { Human Immune Virus and Acquired Immune Deficiency Syndrome } \\ \text { MDG } & \text { Millennium Development Goals } \\ \text { MOEASC } & \text { Ministry of Education, Art, Sport and Culture } \\ \text { MoHCW } & \text { Ministry of Health and Child Welfare } \\ \text { NAC } & \text { National AIDS Council } \\ \text { NAP } & \text { National AIDS Policy } \\ \text { NGO } & \text { Non-Governmental Organisation } \\ \text { RAAAPP } & \text { Rapid Assessment, Analysis and Act Planning Process } \\ \text { SPS } & \text { Schools Psychological Service } \\ \text { SWO } & \text { Social Welfare Officer } \\ \text { UN } & \text { United Nations } \\ \text { UNICEF } & \text { United Nations International Children Emergency Fund } \\ \text { UNAIDS } & \text { Joint United Nations Programme on HIV and AIDS } \\ \text { WHO } & \text { World Health Organisation } \\ \text { ZNOCP } & \text { Zimbabwe National Orphan Care Policy } \\ \text { ZNASP } & \text { Zimbabwe National HIV and AIDS Strategic Plan } \\ & \end{array}$


